\title{
Unsaturated Fluid Flow through Granular Soils Treated with Microbial Induced Desaturation and Precipitation
}

\author{
Elizabeth G. Stallings Young ${ }^{1 *}$, Claudia E. Zapata ${ }^{1}$, and Leon van Paassen ${ }^{1}$ \\ ${ }^{1}$ Department of Civil, Environmental and Sustainable Engineering, Arizona State University, Tempe, AZ 85287, USA
}

\begin{abstract}
The use of microorganisms to induce desaturation of granular soils via denitrification results in nitrogen and carbon dioxide gas generation, which in turn lowers the degree of saturation of the soil matrix. Given sufficient substrates, the stimulated bacteria will produce enough gas to develop a continuous gas phase. Introducing gas into the soil to reduce the degree of saturation is shown to increase the soil resistance to dynamic loading and helps to mitigate liquefaction. The impact of desaturation on liquefaction hazard mitigation has comparative value to the calcite precipitation phase of the process. Meso-scale tests have been performed on a relatively thin tank of soil to simulate planar flow through a granular soil treated with MIDP.
\end{abstract}

\section{Introduction}

Microbial Induced Desaturation and Precipitation (MIDP) is an emerging bio-based ground improvement technique, which has potential for mitigating the potential for earthquake-induced soil liquefaction $[1,2]$. Similar to MICP by urea hydrolysis, precipitation of calcium carbonate minerals by MIDP may increase stiffness, strength and dilatancy or reduce permeability of granular soils by forming cemented wedges between the sand grains. While the biomass has less of a strengthening effect, it may reduce the hydraulic conductivity significantly [3]. Introducing gas into the soil to reduce the degree of saturation is shown to increase the soil resistance to dynamic loading and helps to mitigate liquefaction. The impact of desaturation on liquefaction hazard mitigation has comparative value to the calcite precipitation phase of the process. There are several methods to generate the partially saturated conditions such as gas injection [4], water electrolysis [5], and production of gas in situ through a chemical process [6]. Using biogenic gas through denitrification is another approach that has been reported to be feasible [7-11].

The objective of this study is to evaluate the effect of biogenic gas formation and migration on the volumetric water content and pore water pressure during MIDP treatment in granular soils in two-dimensional plane strain conditions using an instrumented meso-scale tank set-up.

\section{Microbially induced desaturation and precipitation}

The process of MIDP involves injecting an aqueous solution containing calcium, nitrate and a source of dissolved organic carbon (DOC). As a result, indigenous nitrate reducing bacteria are stimulated in situ and convert the nitrate $\left(\mathrm{NO}_{3}{ }^{-}\right)$into nitrogen gas $\left(\mathrm{N}_{2}\right)$, while oxidizing the organic carbon to dissolved inorganic carbon (DIC). In the presence of dissolved calcium, production of DIC results in precipitation of calcium carbonate minerals, while the energy released from the oxidation of DOC is used by the micro-organisms for growth and maintenance. The metabolism can be split in a catabolic and anabolic reactions. When acetate is used as the source of organic carbon the catabolic reaction is:

$$
\begin{aligned}
& \mathrm{C}_{2} \mathrm{H}_{3} \mathrm{O}_{2}{ }^{-}+1.6 \mathrm{NO}_{3}{ }^{-} \rightarrow 0.8 \mathrm{~N}_{2}(\mathrm{~g})+2 \mathrm{HCO}_{3}^{-}+0.2 \mathrm{H}_{2} \mathrm{O}+ \\
& 0.6 \mathrm{OH}^{-}
\end{aligned}
$$

The energy generated by the catabolic reaction (1) will be used by the denitrifying micro-organisms for biomass growth and maintenance. Part of the substrates will be used for the anabolic process or biomass synthesis:

$$
\begin{array}{r}
0.73 \mathrm{C}_{2} \mathrm{O}_{3} \mathrm{H}_{2}{ }^{-}+0.2 \mathrm{NO}_{3}{ }^{-}+0.28 \mathrm{H}_{2} \mathrm{O} \rightarrow \mathrm{CH}_{1.8} \mathrm{O}_{0.5} \mathrm{~N}_{0.2}+ \\
0.45 \mathrm{HCO}_{3}{ }^{-}+0.48 \mathrm{OH}^{-}
\end{array}
$$

The stoichiometry of the complete metabolic reaction may vary, depending on the growth rate of the denitrifying bacteria. At maximum biomass growth, the overall metabolic reaction will be:

$$
\begin{array}{r}
1.21 \mathrm{C}_{2} \mathrm{H}_{3} \mathrm{O}_{2}{ }^{-}+0.97 \mathrm{NO}_{3}{ }^{-}+0.17 \mathrm{H}_{2} \mathrm{O} \rightarrow \mathrm{CH}_{1.8} \mathrm{O}_{0.5} \mathrm{~N}_{0.2}+ \\
0.39 \mathrm{~N}_{2}(\mathrm{~g})+1.41 \mathrm{HCO}_{3}{ }^{-}+0.76 \mathrm{OH}^{-}
\end{array}
$$

Under conditions at which microbial growth is inhibited, the metabolic stoichiometry will follow the catabolic reaction, while the denitrifying organisms just survive and need all energy to maintain themselves. The 
actual stoichiometry of the biochemical conversion depends on the growth rate of the bacteria. The growth rate may be inhibited through several factors, such as limited availability of nutrients, high concentrations of nitrate, or accumulation of intermediate compounds, such as nitrite.

At neutral $\mathrm{pH}$, bicarbonate $\left(\mathrm{HCO}_{3}{ }^{-}\right)$is the dominant inorganic carbon species and the reaction produces alkalinity. In presence of dissolved calcium, the produced bicarbonate may induce precipitation of calcium carbonate $\left(\mathrm{CaCO}_{3}\right)$ :

$$
\mathrm{Ca}^{2+}+\mathrm{HCO}_{3}^{-} \rightarrow \mathrm{CaCO}_{3}(\mathrm{~s})+\mathrm{H}^{+}
$$

The acid production during the precipitation process buffers the $\mathrm{pH}$, while the remaining bicarbonate may form carbon dioxide and transfer to the gas phase:

$$
\mathrm{HCO}_{3}^{-}+\mathrm{H}^{+} \rightarrow \mathrm{CO}_{2}(\mathrm{~g})+\mathrm{H}_{2} \mathrm{O}
$$

When the conversion is complete the only remaining products are biomass $\left(\mathrm{CH}_{1.8} \mathrm{O}_{0.5} \mathrm{~N}_{0.2}\right)$, biominerals $\left(\mathrm{CaCO}_{3}\right)$ and biogas $\left(\mathrm{N}_{2}\right.$ and $\left.\mathrm{CO}_{2}\right)$. The products of the metabolic reaction, biogas $\left(\mathrm{N}_{2}\right.$ and $\left.\mathrm{CO}_{2}\right)$, biomass and biominerals $\left(\mathrm{CaCO}_{3}\right)$ affect the engineering properties of the soil.

\section{Methods and materials}

In this study a stainless-steel tank was used to evaluate the effect of biogenic gas formation and migration on the volumetric water content and pore water pressure during MIDP treatment in granular soils in two-dimensional plane strain conditions. Internal dimensions of the tank were approximately $114 \mathrm{~cm}$ tall, $114 \mathrm{~cm}$ wide and 5.25 $\mathrm{cm}$ thick. The tank had a plexiglass front, which was used for visualization of the gas production. The tank was instrumented with pore pressure transducers (PPT, NXP) connected to a datalogging system (CR6, Campbell Scientific) and moisture sensors to measure volumetric water content (TEROS, Metergroup). The PPTs were arrayed on the back side of the tank with sampling ports protruding into the soil to measure internal pressure changes, while the moisture sensors were embedded in the soil matrix. Figure 1 shows the sensor layout with pore pressure transducers PS10, PS13, and PS15 and moisture sensors MS1-MS3.

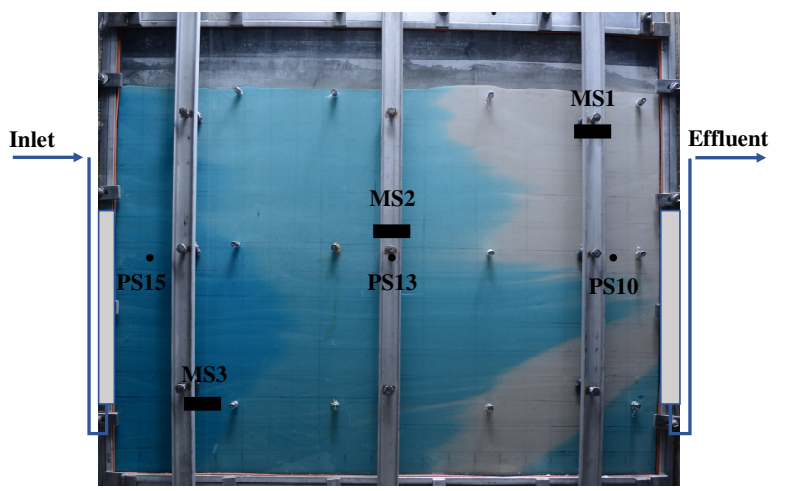

Fig. 1. Tank and sensor layout overlaying and image of the tank during MIDP Injection.
Additionally, time lapse images were taken and processed to visualize the flow of injected fluids and formation and migration of the gas. Injection and extraction ports located on opposite sides of the tank consisted of stainless-steel tubing attached to cylindrical wire meshes to prevent back washing of the granular soils.

The granular soil used in the experiment was a white, siliceous poorly graded sand (US Silica, F60), classified SP according to the Unified Soil Classification System (USCS). The sand was deposited in the tank by wet pluviation through water to ensure saturation and uniform soil packing throughout. Figure 2 shows the grain size distribution of the soil.

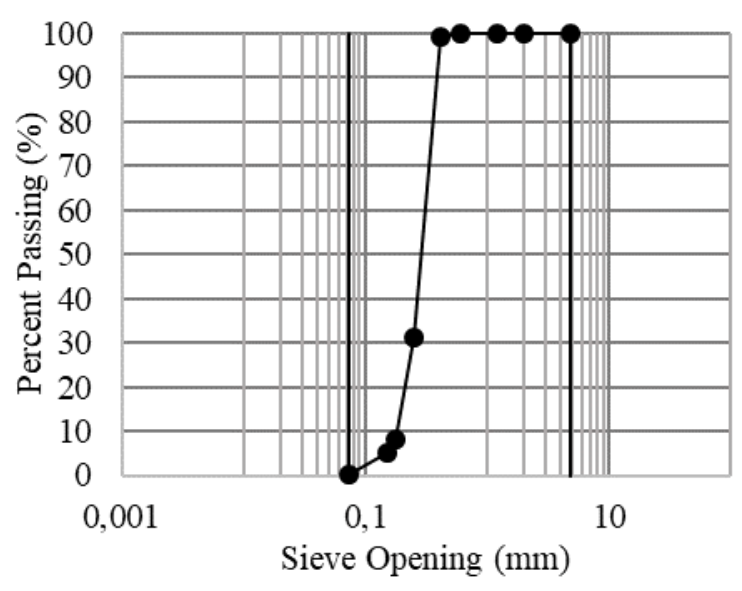

Fig. 2. Grain size distribution of F60 granular soil.

The saturated permeability of the soil was $1.46 \times 10^{-4}$ $\mathrm{m} \mathrm{s}^{-1}$ and the dry density ranged from a maximum a of $1.70 \mathrm{~g} / \mathrm{cm}^{3}$ to a minimum of $1.50 \mathrm{~g} / \mathrm{cm}^{3}$, respectively.

The soil water characteristics curves (SWCC) are important when evaluating the formation, distribution and transport of water and gas phases in partially saturated porous media. The soil water characteristic curve for the sand used in this experiment was determined using the Hyprop system (Metergroup) and is shown in Figure 3. Based on this soil water characteristic curve, which was fitted with van Genuchten model, Equation 6, the air entry value for the sand was determined to be $2.5 \mathrm{kPa}$.

$$
\theta_{w}=\theta_{r}+\frac{\theta_{s}-\theta_{r}}{1+\exp (1)\left[\frac{h-a}{b}\right]}
$$

where:

$\theta_{w}$ is the volumetric water content, which is the ratio of volume of water to total volume

$\theta_{r}$ is the residual volumetric water content

$\theta_{s}$ is the volumetric water content at saturation

$h$ is a soil parameter that is a function of matric suction $a$ is a curve fitting parameter

$b$ is a curve fitting parameter

To simulate the MIDP reaction in the tank, substrate solutions containing $25 \mathrm{mmol} \mathrm{L}^{-1}$ Calcium Acetate (3.95 
$\left.\mathrm{g} \mathrm{L}^{-1}\right)$ and $25 \mathrm{mmol} \mathrm{L}^{-1}$ Calcium Nitrate $\left(4.10 \mathrm{~g} \mathrm{~L}^{-1}\right)$ along with trace elements and salt solutions to promote microbial growth were prepared and injected over a 20 hour period at a constant flow rate of $1.6 \mathrm{~L} \mathrm{hr}^{-1}$. Given the flow rate and pumping time, the substrate injection was estimated to replace a full volume of the fluid in the tank with the substrate solution. The substrate solution was then given a period of 17 days reaction time before being flushed out with water containing no additional substrates.

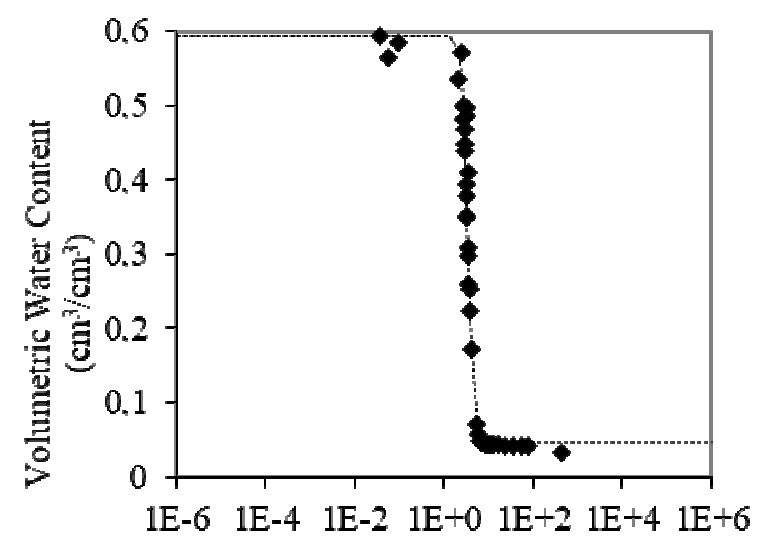

Matric Suction (kPa)

- Experimental Results …-...-.-. van Genuchten

Fig. 3. Soil water characteristic curve of F60 granular soil.

\section{Results and discussions}
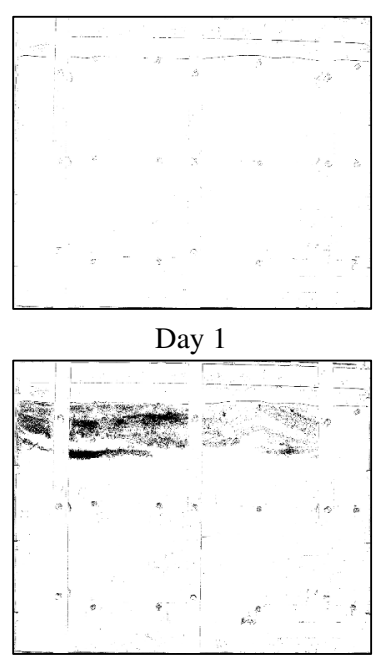

Day 3

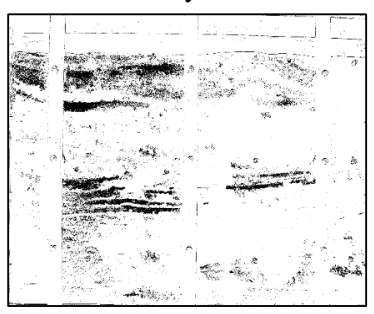

Day 7

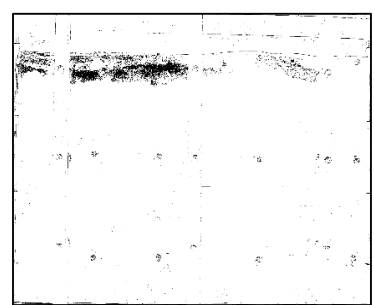

Day 3

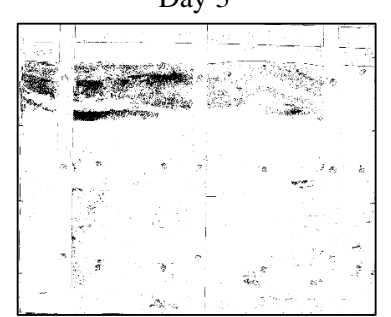

Day 6

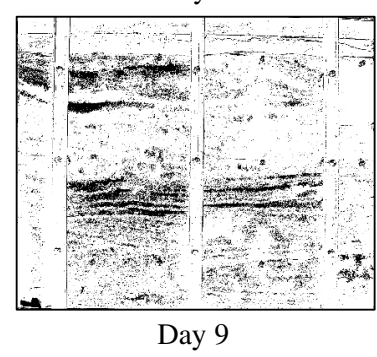

Fig. 4. Processed images depicting gas production over time.
The effectiveness of the MIDP treatment was evaluated using moisture sensors, pore pressure transducers and image processing. The moisture sensors and pore pressure transducers demonstrated that the MIDP treatment was effective in stimulating native bacteria and lowering the degree of saturation of the soil. Figure 4 depicts the accumulation of the gas in the soil matrix from days 1 through 9 post injection, which was derived from processed images. In the images, desaturated zones with gas accumulation are dark in color, while saturated zones remain white.

When substrates were injected into the tank, the injection rate was observed to be greater than the effluent rate, resulting in a temporary elevation of the water level, which drained off freely after the pumps were shut off. This is supported by the day 6 image from Figure 4, which shows gas prevalent in the upper region of the soil matrix, and smaller gas pockets beginning to form in the lower three quarters of the tank. Moisture sensor MS1, as shown in Figure 5, was installed above the elevation of the effluent port, and shows the draining of pore water during the first 5 days as well.

Approximately 4-5 days after the injection began, the substrates sufficiently stimulated denitrifying bacteria for occluded bubbles to form in the pore spaces. This is demonstrated by the pore pressure transducers, shown in Figure 6 , and the moisture sensors, which indicated a significant reduction in moisture content in the soil surrounding the sensors. Pore pressure transducer PS15 shows the first indication of microbial stimulation and gas production followed by PS13 and then PS10 with approximately 36 hours of lag behind PS15. Sensor PS15 was located closest to the injection port and received the access to the substrate solution approximately 12 hours before PS 10 , based on time lapse photos taken during the experiment. Moisture sensors MS2, located in the middle center of the tank, indicated significant desaturation through a rapid decrease in the measured volumetric water content during day 5.

Initially the gases formed into occluded bubbles, which are disconnected from the atmosphere and increase the internal pressure of the bubble until overcoming the air entry pressure of the soil. As more gas is produced, the bubbles accumulate into pockets or lenses of gas. When the pressure in a pocket of gas exceeds the air entry pressure, the gas will temporarily form a continuous gas phase and vent off into the atmosphere lowering the gas pressure in that area. Venting of the gas is indicated by sudden drops in the pressure data, because as the gas is removed from the system into the atmosphere, water flows back into that pore space ultimately lowering the head of water above the pore pressure transducer. Provided additional substrates the process will continue, until sufficient gas has been formed such that a continuous gas phase exists throughout the soil matrix, and the pressure measurements become more stable. This stabilizing effect occurs approximately 14 days after injection and is a function of grain size distribution and the soil water characteristic curve. 


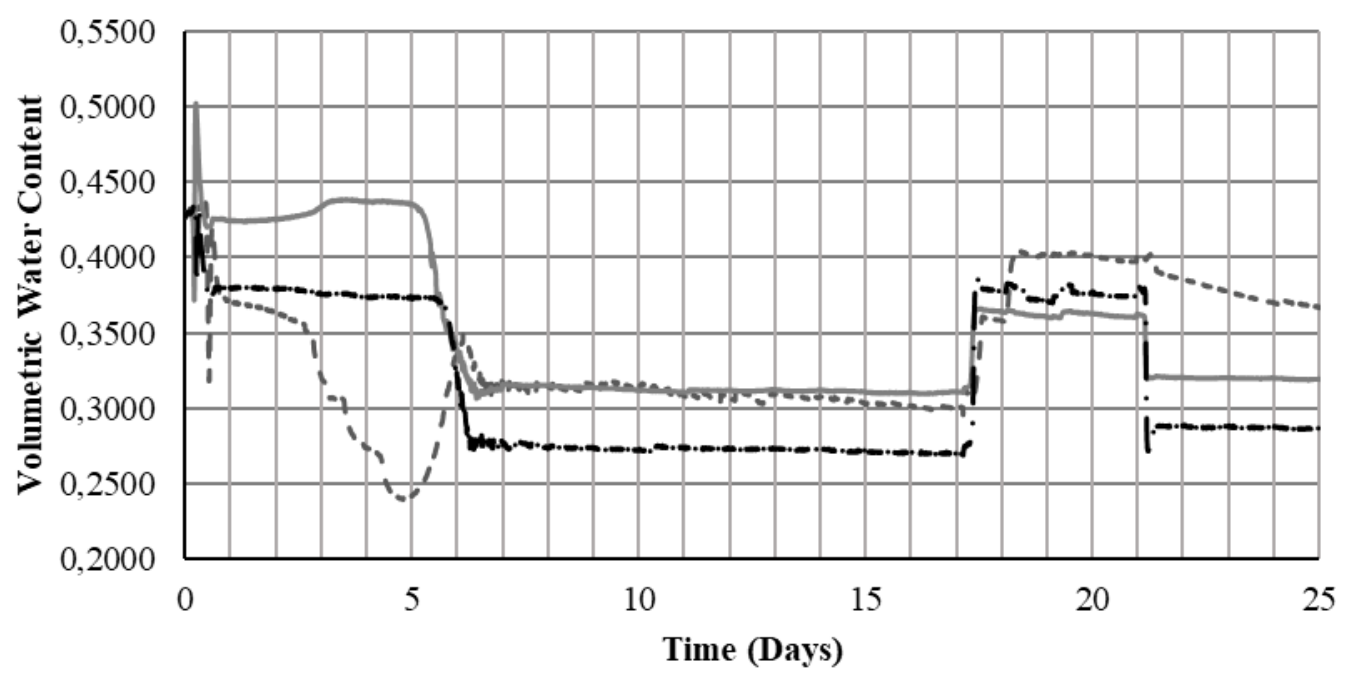

-- MS $1 \longrightarrow$ MS $2-$ MS 3

Fig. 5. Measured volumetric moisture content over time.

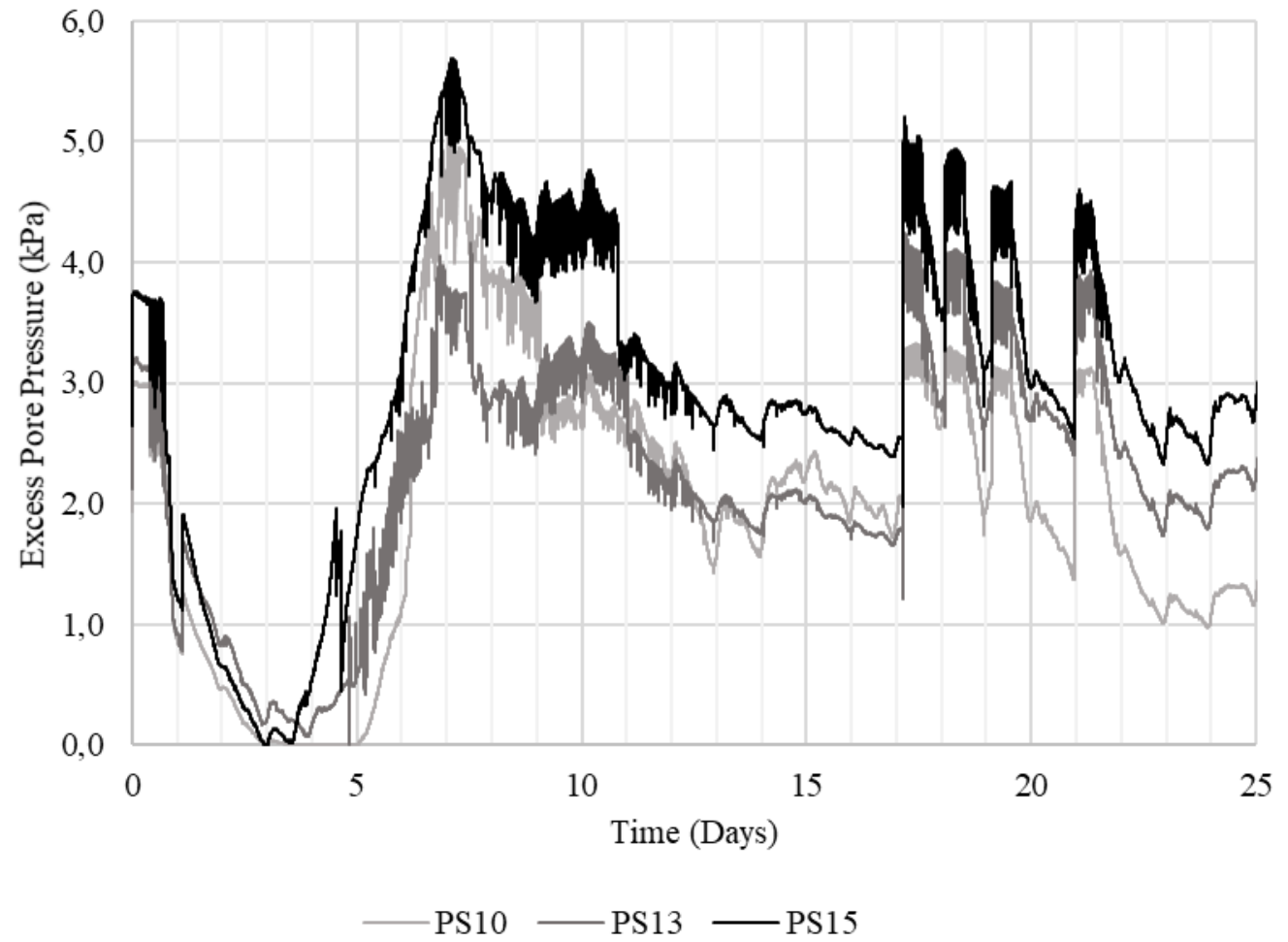

Fig. 6. Excess pore pressure measurements collected during MIDP testing.

After the gas phase stabilized, as indicated by the pressure and moisture data, additional water without substrates was injected into the system, on days 17, 18,19 and 21 , to flush out unreacted substrates and terminate testing. Comparing the excess pore pressure data during the injection of substrates with the data during the final rinsing flushes shows that the pressure difference between sensors 15 and 10 has increased, indicating a reduction of the hydraulic conductivity as a result of desaturation. Secondly, the pressure data during the rinsing flushes shows larger fluctuations due to gas deformation and migration.

The gas phase was considered to be stable based on moisture sensor MS3, located at the bottom of the tank, where it will be unaffected by the draining off of water as the level rises and falls due to gas production. MS 3 indicated approximately $10 \%$ reduction in volumetric water content over the 17-day residence period. When 
the tank was flushed with water to remove excess substrate the volumetric water content only recovered approximately $2.5 \%$. The pore pressure measurements clearly indicate that the gas phase was disturbed due to flushing, resulting in venting off some gas.

\section{Conclusions}

Meso-scale experiments were performed on a relatively thin tank of soil to simulate planar flow through a granular soil treated with MIDP. The treatment successfully desaturated the soil and once a continuous gas phase was formed it remained relatively constant throughout the remainder of the experiment. Flushing with additional water did not remove a significant amount of the biogenic gas. Desaturation resulted in the reduction of hydraulic conductivity and the presence of gas affected the measured excess pore pressure and demonstrates gas migration through the system. Further quantitative analysis is required to elucidate the mechanistic relationships related to MIDP.

\section{Acknowledgements}

The authors would like to acknowledge and thank Nariman Mahabadi for his contributions to experimental set up and his work in image processing.

This material is based upon work primarily supported by the Engineering research Center Program of the National Science Foundation under NSF Cooperative Agreement No. EEC-1449501. Any opinions, findings, and conclusions or recommendations expressed in this material are those of the author(s) and do not necessarily reflect those of the National Science Foundation.

\section{References}

1. O’Donnell, S.T.; Kavazanjian, E.; Rittmann, B.E. MIDP: Liquefaction Mitigation via Microbial Denitrification as a Two-Stage Process. II: MICP. Journal of Geotechnical and Geoenvironmental Engineering 2017, 143, 04017095, doi:10.1061/(ASCE)GT.1943-5606.0001806.

2. O’Donnell, S.T.; Rittmann, B.E.; Kavazanjian, E. MIDP: Liquefaction Mitigation via Microbial Denitrification as a Two-Stage Process. I: Desaturation. Journal of Geotechnical and Geoenvironmental Engineering 2017, 143, 04017094, doi:10.1061/(ASCE)GT.19435606.0001818.

3. Baveye, P.; Vandevivere, P.; Hoyle, B.L.; DeLeo, P.C.; de Lozada, D.S. Environmental impact and mechanisms of the biological clogging of saturated soils and aquifer materials. Critical reviews in environmental science and technology 1998, 28, 123-191.

4. Okamura, M.; Takebayashi, M.; Nishida, K.; Fuji, N.; Jinguji, M.; Imasato, T.; Yasuhara, H.; Nakagawa, E. In-Situ Desaturation Test by Air Injection and Its Evaluation through Field Monitoring and Multiphase Flow Simulation.
Journal of geotechnical and geoenvironmental engineering 2011, 137, 643-652.

5. Yegian, M.; Eseller-Bayat, E.; Alshawabkeh, A.; Ali, S. Induced-partial saturation for liquefaction mitigation: experimental investigation. Journal of Geotechnical and Geoenvironmental Engineering 2007, 133, 372-380.

6. Eseller-Bayat, E.; Yegian, M.K.; Alshawabkeh, A.; Gokyer, S. Liquefaction Response of Partially Saturated Sands. I: Experimental Results. Journal of Geotechnical and Geoenvironmental Engineering 2013, 139, 863-871.

7. Rebata-Landa, V.; Santamarina, J.C. Mechanical Effects of Biogenic Nitrogen Gas Bubbles in Soils. Journal of Geotechnical and Geoenvironmental Engineering 2012, 138, 128-137.

8. He, J.; Chu, J. Undrained Responses of Microbially Desaturated Sand under Monotonic Loading. Journal of Geotechnical and Geoenvironmental Engineering 2014, 140.

9. van Paassen, L.A.; Daza, C.M.; Staal, M.; Sorokin, D.Y.; van der Zon, W.; van Loosdrecht, M.C.M. Potential soil reinforcement by biological denitrification. Ecological Engineering 2010, 36, 168-175, doi:10.1016/j.ecoleng.2009.03.026.

10. Kavazanjian, E., Jr.; O'Donnell, S.T. Mitigation of Earthquake-Induced Liquefaction via Microbial Denitrification: A Two-Phase Process. In IFCEE 2015, 2015; doi:10.1061/9780784479087.212pp. 2286-2295.

11. O'Donnell, S. Mitigation of earthquake-induced soil liquefaction via microbial denitrification: A twostage process Dissertation, Arizona State University, ProQuest Dissertations \& Theses Global, 2016. 